\title{
Rationalizing photo-triggered hydrogen evolution using polypyridine cobalt complexes: substituent effects on hexadentate chelating ligands
}

\author{
Fiorella Lucarini, ${ }^{[a]}$ David Bongni, ${ }^{[a]}$ Philippe Schiel, ${ }^{[a]}$ Gabriele Bevini, ${ }^{[b]}$ Elisabetta Benazzi, ${ }^{[b]}$ Euro

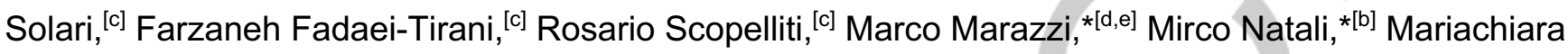 \\ Pastore, ${ }^{*[]}$ Albert Ruggi ${ }^{*[a]}$
}

[a] Dr. F. Lucarini, D. Bongni, P. Schiel, Dr. A. Ruggi

Université de Fribourg

Département de Chimie

Chemin du Musée 9, 1700 Fribourg (Switzerland)

E-mail: albert.ruggi@unifr.ch

[b] G. Bevini, Dr. E. Benazzi, Prof. Dr. M. Natali

Università degli studi di Ferrara

Dipartimento di Scienze Chimiche, Farmaceutiche ed Agrarie

Via L. Borsari 46, 44121 Ferrara (Italy)

E-mail: mirco.natali@unife.it

[c] Dr. E. Solari, Dr. F. Fadaei-Tirani, Dr. R. Scopelliti

Institut des Sciences et Ingénierie Chimique

École Polytechnique Fédérale de Lausanne (EPFL)

1015 Lausanne (Switzerland)

[d] Prof. Dr. M. Marazzi

Department of Analytical Chemistry, Physical Chemistry and Chemical Engineering

Universidad de Alcalá

Ctra. Madrid-Barcelona Km. 33,600, E-28805 Alcalá de Henares (Madrid) (Spain)

E-mail: marco.marazzi@uah.es

[e] Prof. Dr. M. Marazzi

Chemical Research Institute "Andrés M. del Río" (IQAR)

Universidad de Alcalá, E-28871 Alcalá de Henares (Madrid) (Spain)

[f] Dr. M. Pastore

Université de Lorraine \& CNRS

Laboratoire de Physique et Chimie Théoriques (LPCT)

F-54000, Nancy (France)

E-mail: mariachiara.pastore@univ-lorraine.fr

Supporting information for this article is given via a link at the end of the document.

\begin{abstract}
We report four novel polypyridine cobalt(II) complexes based on a hexadentate ligand scaffold bearing either electron withdrawing $\left(-\mathrm{CF}_{3}\right)$ or electron donating $\left(-\mathrm{OCH}_{3}\right)$ groups in different positions of the ligand. Experiments and theoretical calculations have been combined to perform a systematic investigation of the effect of the ligand modification on the hydrogen evolution reaction. The results indicate that the position, rather than the type of substituent, is the dominating factor in promoting catalysis. The best performances are observed upon introduction of substituents on the pyridine moiety of the hexadentate ligand, which promotes the formation of the $\mathrm{Co}(\mathrm{II}) \mathrm{H}$ intermediate via intramolecular proton transfer reactions with low activation energy. Quantum yields of $11.3 \%$ and of $10.1 \%$, maximum turnover frequencies of $86.1 \mathrm{~min}^{-1}$ and $76.6 \mathrm{~min}^{-1}$, and maximum turnover numbers of 5520 and 4043 were obtained respectively with a $-\mathrm{OCH}_{3}$ and a $-\mathrm{CF}_{3}$ substituent.
\end{abstract}

\section{Introduction}

The development of renewable and clean energetic solutions is prompted by a number of environmental issues such as global warming and large-scale pollution resulting from extensive use of fossil fuels. Storing solar energy as chemical bonds (e.g. $\left.\mathrm{H}_{2}\right)$ is particularly promising for the safeguard of our planet and for the production of clean sources of energy. ${ }^{[1]}$ In fact, the combustion of hydrogen releases a great amount of energy and produces water as the sole product. ${ }^{[2]}$ Ideally sunlight can drive processes such as the splitting of water, allowing the exploitation of the energy coming from the Sun through the formation of $\mathrm{H}_{2}$ and $\mathrm{O}_{2}$. Water splitting consists of two separate half reactions: the reduction of protons to produce hydrogen and the oxidation of water to give oxygen. Focusing the attention only on the reductive part of the water splitting process, the optimization of the components driving the reaction, such as light harvesting 
materials (i.e. photosensitizers), sacrificial electron donors and catalysts, is fundamental for the development of an efficient $\mathrm{H}_{2}$ production process. ${ }^{[3]}$ When compared to heterogeneous materials, homogeneous molecular catalysts for the reduction of protons offer the advantage of well-defined structures and tunable reactivity. ${ }^{[4]}$ Numerous complexes based on earth-abundant metals such as $\mathrm{Ni}^{[5]} \mathrm{Fe}^{[6]}$ and in particular $\mathrm{Co}^{[7]}$ have been developed as catalysts for electro- and photochemical hydrogen

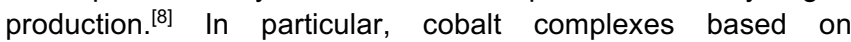
pentadentate or tetradentate polypyridyl ligands have shown high catalytic activity towards hydrogen evolution in fully aqueous solutions, but the improvement of their efficiency and stability remains a great challenge. ${ }^{[7 b]}$ Moreover, the relationship between structure and activity of such catalysts is not always clear and general rules concerning the effect of modifications of the ligands on the catalytic activity could not be extrapolated so far. Nevertheless, it is certain that the chemical nature of the ligand can affect the performance of the corresponding catalyst. In particular, the substituent effects - both electronic and steric induced by functionalization of the ligands can alter the activity, as evidenced by the analysis of some catalysts reported in literature (Scheme 1). More in detail, Chang, Long, Yang and coworkers, in 2013, studied the photochemical hydrogen production for a series of cobalt complexes based on a pentapyridyl ligand containing an electron withdrawing group (EWG) (1) or an electron donating group (EDG) (2) into the para- position of the axial pyridine. The catalyst containing an EWG (i.e. $-\mathrm{CF}_{3}, 1$ ) was found to be twice as active as the catalyst with an EDG (i.e. $\left.\mathrm{N}\left(\mathrm{CH}_{3}\right)_{2}, 2\right) .{ }^{[9]}$ However, an opposite trend was found by Chang, Long, Castellano and co-workers for polypyridyl complexes containing also bipyridine moieties. The authors reported that in pentadentate ligands based on two bipyridines and one pyridine unit, the presence of $-\mathrm{CF}_{3}(3)$ in the para- position of the pyridyl moiety leads to a small decrease in activity with respect to the catalyst with no substituents (i.e. -H) (4). ${ }^{[10]}$ The same authors observed that the effect of the EWG is even higher for tetradentate ligands with one bipyridine and two pyridine groups: in this case, the introduction of a - $\mathrm{CF}_{3}$ group into the para- position of two pyridyl moieties (5) decreases by ca. 5 times the activity with respect to the catalyst with only $H(6) .{ }^{[11]}$ This seems to indicate that the same substituent can induce opposite effects, depending on the functionalized chelating ligand, regardless of its electronic nature. Recently, Alberto, Probst and co-workers introduced EDGs (i.e. $-\mathrm{OCH}_{3}$ ) on the bipyridine moieties. The authors observed that for a tetradentate ligand with two pyridines and one bipyridine group, the introduction of two methoxy groups into the para- position of the bipyridines (7) increases the rate of the catalysis compared to the catalyst with $\mathrm{H}(\mathbf{8})$ in the same positions. By contrast, for the pentadentate ligand with two bipyridine groups and one pyridine the introduction of methoxy substituents (9) induces lower stability and catalytic rate with respect to the analogous catalyst with no substituents (10), hence possibly pointing toward the interplay of electronic substituent effects on the ligand and steric strain of the overall metal complex. ${ }^{[12]}$ In any case, from this short survey of literature results, it is evident that the question of structure-activity relationships concerning cobalt-based catalysts is still object of debate and more investigations are needed, with the aim of rationally modulating the hydrogen photoproduction properties.

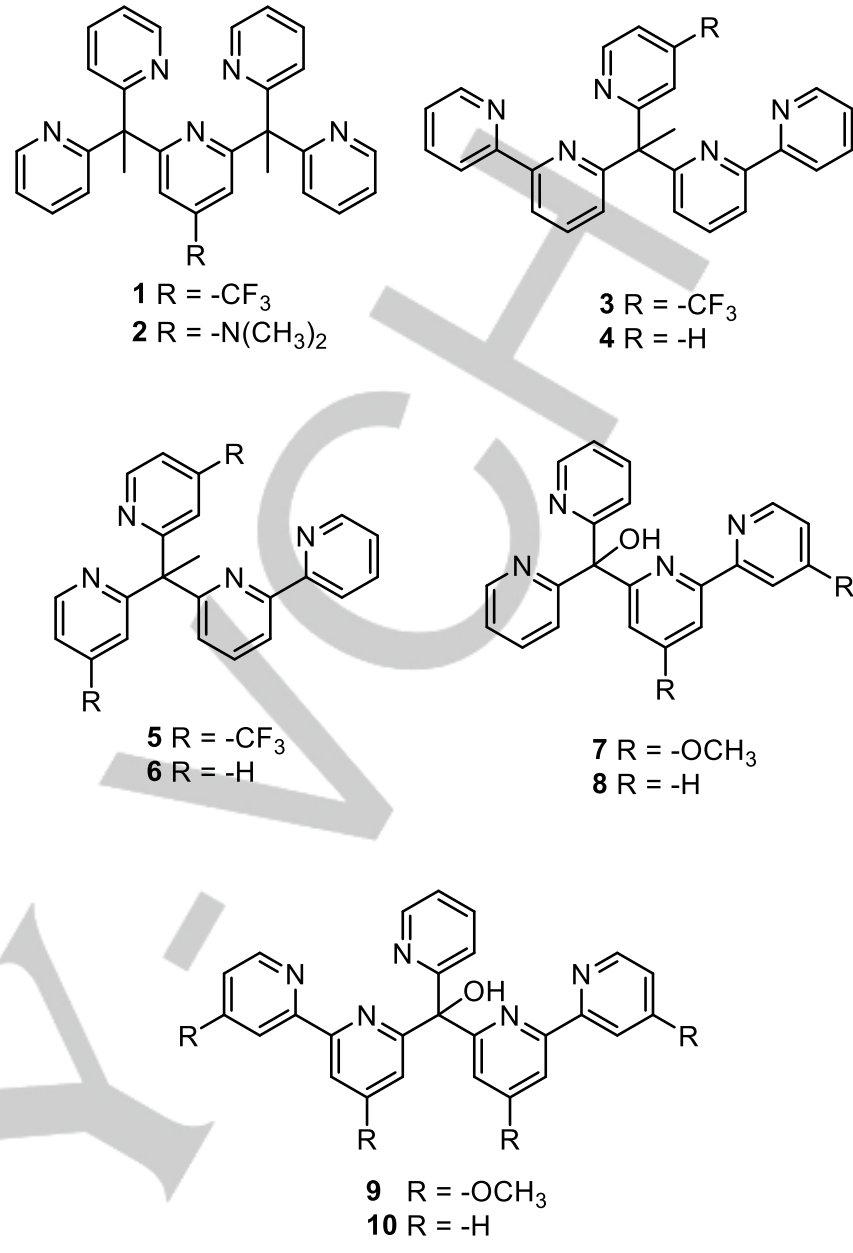

Scheme 1. Polydentate ligands used for hydrogen evolution photoreaction.

Following the strategy of using a single polydentate ligand (that ensures a unique design of the stereochemistry of the metal complex, avoiding the presence of different isomers), we have recently reported the first heptacoordinate cobalt complexes (CO and $\left.\mathbf{C O}^{\prime}\right)^{[13]}$ characterized by a surprisingly high activity towards photochemical hydrogen production in aqueous media (Scheme 2). Herein, we study a new series of heptacoordinate cobalt polypyridyl complexes based on the modification of the DBPyPyA (where DBPy-PyA: 1-([2,2'-bipyridin]-6-yl)-N-([2,2'-bipyridin]6 -ylmethyl)-N-(pyridin-2-ylmethyl)methanamine) ligand scaffold bearing $-\mathrm{CF}_{3}$ or $-\mathrm{OCH}_{3}$ into the para- position of the pyridine or of the bipyridine moieties (Scheme 2).

By coupling experiments and theoretical calculations, here we aim at rationalizing the different parameters leading to hydrogen photoproduction, in order to establish a relationship between the design of this family of cobalt complexes and their overall catalytic performance, at the same time getting mechanistic insights into the different steps required to generate $\mathrm{H}_{2}$. Especially, both electron donating and withdrawing substituent groups will be considered, functionalizing either pyridine or bipyridine moieties. In this way, a direct and systematic comparison between them and the unsubstituted complex could reveal how subtle modifications of the structural properties can determine consistent 
shifts in the complex energetics and thus in the $\mathrm{H}_{2}$ production performance.

Apart from the catalyst itself, particular attention should be given also to the catalytic conditions such as solvents, light sources or electron donors, since different experimental conditions inhibit the direct comparison of catalysts studied by different groups. ${ }^{[14]}$ Moreover, these conditions could play a role in optimizing the catalytic process. In this study, photochemical experiments were applied to scrutinize the step-by-step $\mathrm{H}_{2}$ production, finally establishing the overall mechanistic scenario.

\section{Results and Discussion}

\section{Synthesis and characterization}
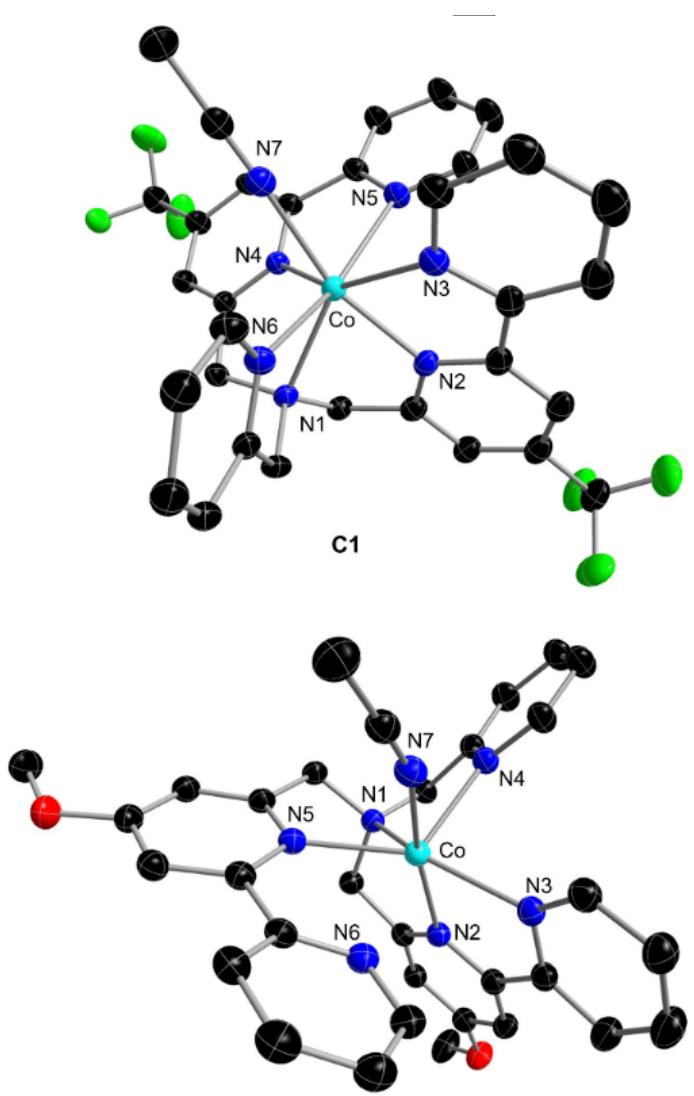

C3

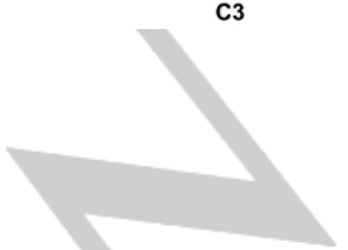

Figure 1. Crystal structures of the functionalized complexes along with atoms labelling scheme for first coordination sphere. Solvent molecules ( $\left.\mathrm{CH} \mathrm{H}_{3} \mathrm{CN}\right)$, counterions $\left(\mathrm{BF}_{4}{ }^{-}\right)$, and $\mathrm{H}$ atoms have been omitted for clarity. Color code: Co (turquoise), N (blue), O (red), C (black), $\mathrm{H}$ (white), B (orange) and F (green).

Cobalt complexes were prepared by mixing the corresponding ligand and $\mathrm{Co}\left(\mathrm{BF}_{4}\right)_{2} \cdot 6 \mathrm{H}_{2} \mathrm{O}$ in $\mathrm{MeOH}$ at room temperature. The performed under the same conditions for each catalyst using $\mathrm{Ru}(\mathrm{bpy}) 3^{2+}$ (where bpy $=2,2^{\prime}$-bipyridine), as photosensitizer and ascorbic acid as electron donor in aqueous solutions. Transient absorption spectroscopy allowed the investigation of the intermediates involved during photocatalytic hydrogen evolution and the comparison of the kinetics of catalyst reduction by photogenerated $\mathrm{Ru}(\mathrm{bpy}) 3^{+}$. Density functional theory (DFT) was
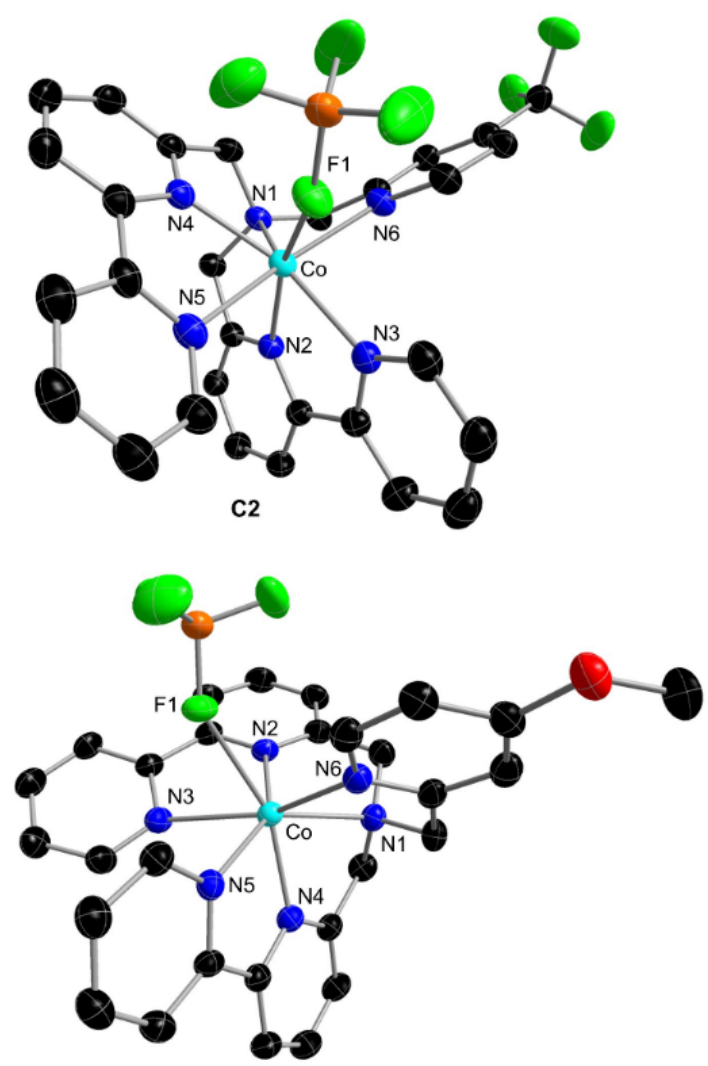

C4

Scheme 2. Heptacoordinate Co complexes studied in this work. The counterions of the complexes are: $\mathrm{Cl}^{-}$for $\mathrm{CO}, \mathrm{PF}_{6}{ }^{-}$for $\mathrm{CO}^{\prime}$ and $\mathrm{BF}_{4}^{-}$for all the other complexes. 
Single crystals suitable for X-ray diffraction were grown by slow diffusion of diethyl ether into acetonitrile solutions of the complexes. From the analysis of the crystallographic structures of the complexes (Figure 1) it can be concluded that C1, C2 and C4 display a heptacoordinate geometry, although $\mathbf{C} \mathbf{1}$ completes the coordination sphere with a solvent molecule, i.e., $\mathrm{CH}_{3} \mathrm{CN}$, while C2 and C4 with a counterion, i.e., $\mathrm{BF}_{4}^{-}$. On the other hand, C3 looks at a first sight as a hexacoordinate structure, due to the long Co-N6 distance (2.472(8) $\AA$ vs. an average of 2.21 shown by the other complexes of the family). Nevertheless, the spatial arrangement of the atoms around the metal center in $\mathbf{C} 3$ is close to that observed for the heptacoordinate complexes $\mathbf{C 1}, \mathbf{C 2}$ and C4, giving rise to a $\mathbf{C 3}$ pseudo-heptacoordinate geometry. Details of the X-ray structures are given in SI (Section 10). It should be pointed out that, whilst seven coordination is evident in the solid state, the weakly bound ligands $\left(\mathrm{BF}_{4}^{-}\right.$or $\left.\mathrm{CH}_{3} \mathrm{CN}\right)$ are likely released in aqueous solution. This would lead to a similar coordination environment around the cobalt center for all C0-C4 complexes. Indeed, this observation is corroborated by the analysis of UV-Vis absorption spectra in water (see SI, Figure S1), which are very similar, except for the obvious differences in the UV region ascribable to the different bipyridine ligands. All complexes showed paramagnetic properties and the magnetic moments calculated with the Evans method gave values between 3.8 and $4.3 \mathrm{BM}$, as expected for a cobalt metal center in a highspin configuration (Figure S2). ${ }^{[13,15]}$

\section{Electrochemical characterization}

Cyclic voltammetry (CV) experiments of cobalt complexes C1-4 were performed in order to get information on the relevant reduction processes. The CVs of each complex feature two sets of reduction waves (Table 1, Figure S3). The first reduction, at more positive potentials, is assigned to a metal centered reduction implying the generation of a $\mathrm{Co}(\mathrm{I})$ species. Isodensity plots of the "redox active orbitals" (Figure S16) and the calculated Mulliken charges (Table S1) show that a consistent fraction of the added electronic charge is localized on the metal center. However, the BPY2 ligand (nomenclature given in Figure S15) is also largely involved in the process, similarly to what found for $\mathbf{C 0}$ in our previous work. ${ }^{[16]}$ The second reduction(s), at more negative potentials, is assigned to reduction(s) centered on the bipyridine ligands, and essentially on BPY1, as it is apparent in Figure S16. In this case, Mulliken charges do not indicate additional electronic density on the cobalt atom ${ }^{\left[{ }^{[16]}\right.}$ As to the second reduction process, a single two-electron wave is observed for all complexes except for $\mathbf{C 1}$, for which two well separated one-electron waves are observed at similar potentials (Table 1). This can be related to the possible detachment of one bipyridine ligand upon one-electron reduction of the metal complex (see below) that makes the two bidentate ligands intrinsically different from a chemical point of view. As expected based on the electronic nature of the substituent, ${ }^{[7 \mathrm{~b}, 9-11]}$ the presence of EWGs on the bipyridine moiety in $\mathbf{C} 1$ leads to significant positive shifts of the potentials of both metal- and ligand-based redox processes when compared to the parent complex C0', whereas the presence of EDGs in C3 leads to a negative shift. On the other hand, the introduction of both EWGs and EDGs on the pyridine moiety has a very minor effect on the reduction potentials, whose values are comparable to those of the unsubstituted complex C0'. This is consistent with the fact that the electronic effect on the cobalt center is mainly imparted by the bipyridine ligands rather than by the pyridine group. Overall, the calculated values (Table 1) nicely match the experimental values and trend, confirming the soundness of the employed level of theory.

Table 1. Experimental and calculated reduction potentials $\left(\mathrm{E}_{1 / 2}, \mathrm{~V}\right) \mathrm{vs}$. $\mathrm{Fc}_{\mathrm{Fc}} \mathrm{Fin}^{+}$ acetonitrile. Cyclic voltammetry $(\mathrm{CV})$ performed on $1 \mathrm{mM}$ solution of complexes in $\mathrm{CH}_{3} \mathrm{CN}$ with 0.1 TBAPF$_{6}$ using glassy carbon as the working electrode, $\mathrm{Pt}$ as the counter electrode, a silver wire as quasi-reference electrode, and ferrocene as internal standard. ${ }^{[17]}$ Calculated absolute potentials were obtained vs. vacuum and converted vs. $\mathrm{Fc} / \mathrm{Fc}^{+}$by adding $-4.80 \mathrm{eV}$, according to ref. ${ }^{[18]}$

\begin{tabular}{lcccc}
\hline & \multicolumn{2}{c}{ Experiments } & \multicolumn{2}{c}{ Calculations } \\
\hline & $\begin{array}{c}\text { First } \\
\text { Reduction }\end{array}$ & $\begin{array}{c}\text { Second } \\
\text { Reduction }\end{array}$ & $\begin{array}{c}\text { First } \\
\text { reduction }\end{array}$ & $\begin{array}{c}\text { Second } \\
\text { reduction }\end{array}$ \\
\hline C0' & -1.49 & $-2.03^{[\mathrm{a}]}$ & -1.45 & -2.10 \\
C1 & -1.29 & $-1.73^{\prime},-1.85^{-1.5}$ & -1.23 & -1.78 \\
C2 & $-1.48^{[a, b]}$ & -1.46 & -2.07 \\
C3 & $-1.59^{[a]}$ & $-2.13^{[a]}$ & -1.62 & -2.17 \\
C4 & -1.51 & $-2.04^{[a]}$ & -1.50 & -2.12 \\
\hline
\end{tabular}

[a] Two-electron wave; [b] irreversible wave, peak potential given.

Table 2. Mid-wave potentials $\left(E_{c a t}, V\right)$ and overpotentials $(\eta, V)$ for catalytic proton reduction (averaged over three TFA concentrations) estimated by cyclic voltammetry $(\mathrm{CV})$ performed in $\mathrm{CH}_{3} \mathrm{CN}$, with $0.1 \mathrm{TBAPF}_{6}$ using glassy carbon as the working electrode, $\mathrm{Pt}$ as the counter electrode, a silver wire as quasireference electrode, and ferrocene as internal standard.

\begin{tabular}{ccc}
\hline & $\mathrm{E}_{\text {cat }}{ }^{[\mathrm{a}]}$ & $\eta^{[\mathrm{b}]}$ \\
\hline $\mathbf{C 0} \mathbf{r}^{\prime}$ & -1.41 & 0.74 \\
$\mathbf{C 1}$ & $-1.18,-1.59^{[\mathrm{c}]}$ & $0.51,0.92^{[\mathrm{c}]}$ \\
$\mathbf{C 2}$ & -1.36 & 0.69 \\
$\mathbf{C 3}$ & -1.49 & 0.82 \\
$\mathbf{C 4}$ & -1.42 & 0.75 \\
\hline
\end{tabular}

[a] estimated according to ref. ${ }^{[19]}$ from the maximum of the first derivative of the forward scan and subtracting $15 \mathrm{mV}$; [b] estimated as $\eta=E(T F A)-E_{c a t}$ using the reduction potential of TFA in acetonitrile calculated from ref. ${ }^{[19]}[c](E) E C E C$ mechanism.

Addition of trifluoroacetic acid (TFA) to an acetonitrile solution of each cobalt complex triggers the appearance of irreversible waves (Figure 2 for C1-C4, Figure S4 for C0') which can be attributed to catalytic proton reduction to dihydrogen, as demonstrated from bulk electrolysis experiments with the parent

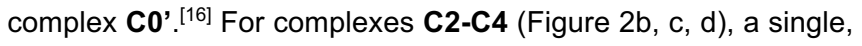
intense catalytic wave emerges at potential close to the $\mathrm{Co}(\mathrm{II}) / \mathrm{Co}(\mathrm{I})$ redox process and displays mid-wave potentials $\left(E_{c a t}\right)^{[19]}$ which fall at more positive values than the $\mathrm{Co}(\mathrm{II}) / \mathrm{Co}(\mathrm{I})$ reduction event and are appreciably independent of the TFA concentration (Table 2). 

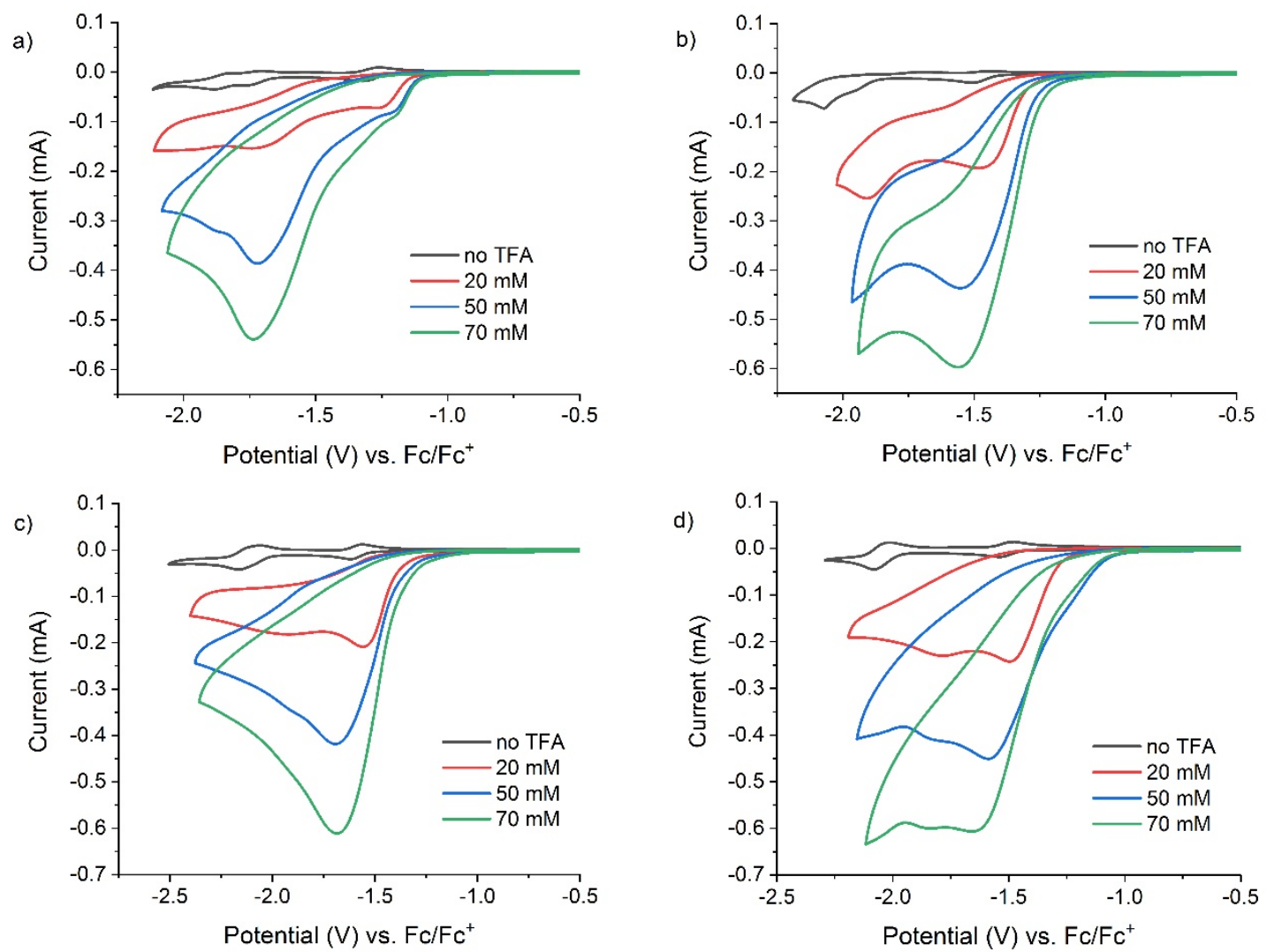

Figure 2. Cyclic voltammetry of $1 \mathrm{mM}$ solutions of a) $\mathbf{C 1}$, b) $\mathbf{C 2}$, c) $\mathbf{C 3}$, and d) $\mathbf{C} 4$ recorded in acetonitrile (0.1 M TBAPF $)$ in the presence of 0-70 mM TFA at a scan rate of $0.1 \mathrm{~V} / \mathrm{s}$ using glassy carbon (GC) as the working electrode (WE), $\mathrm{Pt}$ as the counter electrode (CE), Ag wire as the quasi reference (RE), and ferrocene as internal standard.
a) $\mathrm{Co}(\mathrm{II}) \stackrel{\mathrm{e}^{-}}{\longrightarrow} \mathrm{Co}(\mathrm{I}) \stackrel{\mathrm{H}^{+}}{\longrightarrow} \mathrm{Co}(\mathrm{I})-\mathrm{LH} \stackrel{\mathrm{e}^{-}}{\longrightarrow} \mathrm{Co}(\mathrm{II})-\mathrm{H} \stackrel{\mathrm{H}^{+}}{\longrightarrow} \mathrm{Co}(\mathrm{II})+\mathrm{H}_{2}$
b) $\mathrm{Co}(\mathrm{II}) \stackrel{\mathrm{e}^{-}}{\longrightarrow} \mathrm{Co}(\mathrm{I}) \stackrel{\mathrm{e}^{-}}{\longrightarrow} \mathrm{Co}(\mathrm{I})-\mathrm{L}^{(-)} \stackrel{\mathrm{H}^{+}}{\longrightarrow} \mathrm{Co}(\mathrm{I})-\mathrm{L}^{(-)} \mathrm{H} \stackrel{\mathrm{e}^{-}}{\longrightarrow} \mathrm{H}-\mathrm{Co}(\mathrm{II})-\mathrm{L}^{(-)} \stackrel{\mathrm{H}^{+}}{\longrightarrow} \mathrm{Co}(\mathrm{I})+\mathrm{H}_{2}$

Scheme 3. a) General catalytic mechanism for hydrogen evolution by cobalt complexes C0'-C4; b) alternative mechanism at large overpotentials in C1 (L stands for the bipyridine ligand).

This can be taken as an indication ${ }^{[20]}$ that, similarly to $\mathbf{C O}^{\prime},{ }^{[16]}$ for complexes C2, C3, and C4 an ECEC catalytic mechanism is operating (Scheme 3a), which implies two alternated reduction/protonation steps before hydrogen elimination. Interestingly, the overpotential $(\eta)$ for proton reduction (Table 2) is comparable in the case of complexes C0', C2, and C4, while it is substantially larger in the case of complex $\mathbf{C} 3$, thus suggesting that the substitution on the bipyridines has a stronger impact on the overpotential required for proton reduction than the substitution on the pyridine.

While a single, predominant catalytic wave is disclosed in the case of $\mathbf{C 2}, \mathbf{C} 3$, and $\mathbf{C 4}$, a peculiar behavior is observed in the case of complex $\mathbf{C} 1$ (Figure 2a). As a matter of fact, two catalytic processes can be clearly distinguished which differ on both potential and maximum current. The first catalytic event occurs at potentials compatible with the $\mathrm{Co}(\mathrm{II}) / \mathrm{Co}(\mathrm{I})$ redox step and displays a positive shift of the mid-wave potential, compatible with an ECEC mechanism (Scheme 3a) as observed for all cobalt complexes. The associated overpotential (Table 2) is the lowest among the series and consistent with the electronic effects exerted by the EWGs on the bipyridines. However, the reduced currents associated to this mechanism, compared to those of the other complexes in the series, strongly suggests that this ECEC catalytic process is slow and thus inefficient. This can be ascribed to the lower basicity of the cobalt center upon reduction due to the stabilization provided by the EWGs on the bipyridine ligands. On the other hand, the second catalytic wave is more intense and rises up at more negative potentials than the $\mathrm{Co}(\mathrm{II}) / \mathrm{Co}(\mathrm{I})$ reduction, but at more positive values than the ligand-based redox process. Thus, it can be assigned ${ }^{[20]}$ to a parallel mechanism of the type (E)ECEC (Scheme 3b) involving two alternated reduction/protonation steps occurring after a first electron transfer. The requirement of an additional charging process to initiate the catalysis translates into a larger overpotential for proton reduction by $\mathbf{C} \mathbf{1}$ via this latter mechanism (Table 2).

\section{Light-driven hydrogen evolution}

Photochemical $\mathrm{H}_{2}$ production experiments were carried out in acetate buffer $(1.0 \mathrm{M})$ at $\mathrm{pH} 4.0$ in the presence of the catalyst (1 
$\mu \mathrm{M}), \mathrm{Ru}(\mathrm{bpy}){ }_{3}{ }^{2+}(0.5 \mathrm{mM})$ and ascorbic acid $(0.1 \mathrm{M})$ at $20^{\circ} \mathrm{C}$ upon irradiation with a LED light at $475 \mathrm{~nm}$. The experimental conditions were chosen according to previously optimized data for the parent complex $\mathrm{C} 0 .^{[13]}$ Hydrogen evolution quantum yields were measured by using a $\mathrm{Ru}(\mathrm{bpy}) 3^{2+} / 9,10$-diphenylanthracene actinometer. ${ }^{[21]} \mathrm{A}$ complete description of the process is given in Supporting Information (Section 9).
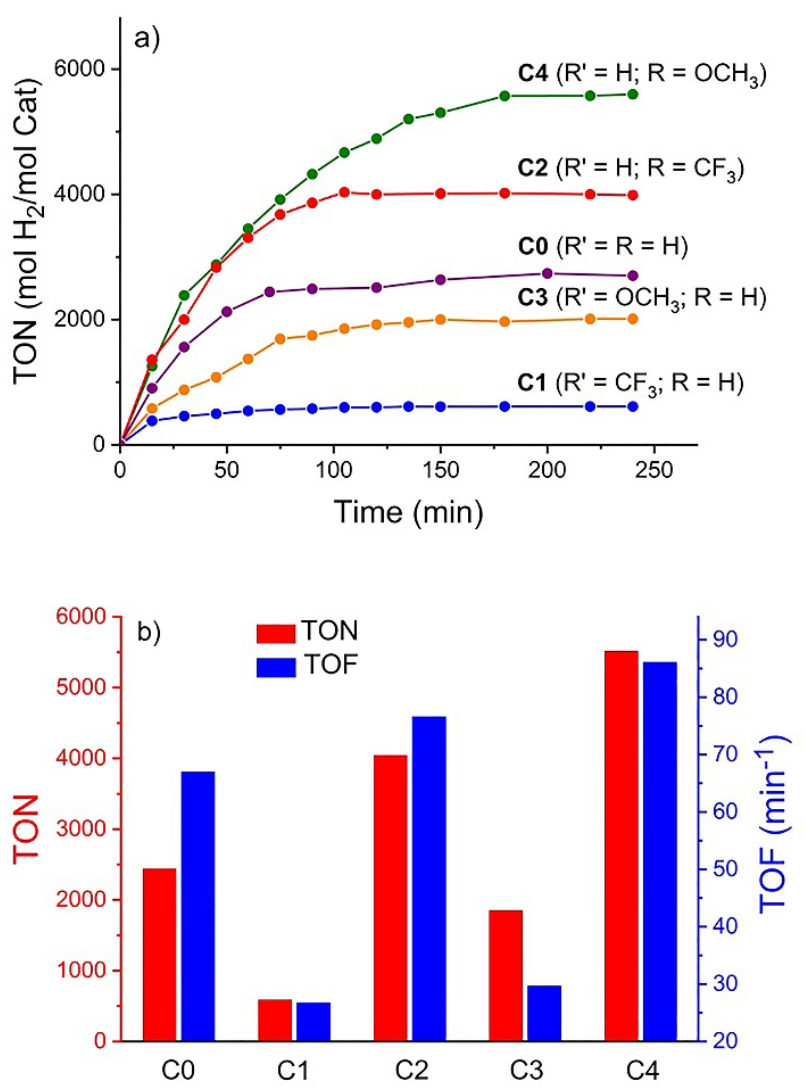

Figure 3. a) $\mathrm{H}_{2}$ evolved expressed in $\mathrm{TON}\left(\mathrm{mol} \mathrm{H}_{2}\right)(\mathrm{mol} \text { Cat. })^{-1}$ over time. The solutions containing 1.0 M acetate buffer at pH 4.0, 0.1 M ascorbic acid, $0.5 \mathrm{mM}$ $\mathrm{Ru}(\mathrm{bpy}) 3^{2+}$ and $1 \mu \mathrm{M}$ catalyst were irradiated at $475 \mathrm{~nm}$ with a LED light at $20^{\circ} \mathrm{C}$. b) maximum TONs and TOFs.

As shown in Figure 3 the highest turnover number (TON, expressed as $\left(\mathrm{mol} \mathrm{H}_{2}\right)\left(\mathrm{mol} \mathrm{Cat}^{-1}\right)$ of 5520 and the lower TON of $591 \mathrm{~mol} \mathrm{H}_{2} / \mathrm{mol}$ catalyst, are achieved by $\mathbf{C} 4$ and $\mathbf{C 1}$, respectively. C2 reaches a maximum TON of 4043 followed by $\mathbf{C} 3$ with a TON of 1853. In terms of maximum turnover frequencies (TOFs, expressed as $\left(\mathrm{mol} \mathrm{H}_{2}\right)$ (mol Cat. $)^{-1}(\mathrm{~min})^{-1}$, calculated in the initial part of the kinetic traces, see Supporting Information Sections 1 and 9 for further details), higher values are obtained with $\mathbf{C 2}$ and C4 (i.e., maximum TOFs of 76.6 and $86.1 \mathrm{~min}^{-1}$ ) with respect to C3 and C1 (i.e., maximum TOFs of 29.7 and $26.7 \mathrm{~min}^{-1}$ ). C0 ranks in the middle of the two different electronic groups with a TON of 2440 and a maximum TOF of $67.0 \mathrm{~min}^{-1}$. Quantum yield values were estimated to be $3.5 \%, 10.1 \%, 3.9 \%, 11.3 \%$ and $8.8 \%$ for $\mathbf{C 1}$, C2, C3, C4 and C0 respectively. In order to compare the photochemical data on a more quantitative basis, we should first stress the main differences between the figure-of-merits we have estimated in the light-driven hydrogen evolution experiments and their actual role in the definition of the photochemical performance. ${ }^{[22]}$ The maximum TON is indeed a metric of the stability of the photocatalytic system, whereas the quantum yield (and under the present experimental conditions also the maximum TOF) is a suitable parameter which accounts for the efficiency of the light-to-hydrogen conversion process. Although being apparently independent one with respect to the other, these two parameters (TON and quantum yield) are usually interrelated considering that a poorly efficient system is expected to be also poorly stable since parasite reactions, originating from (photo)catalytic intermediates, might be competitive with hydrogen formation thus enhancing deactivation routes. ${ }^{[23]}$ In this respect, the trend of both TON and quantum yields are apparently similar throughout the whole series except for complex C1 for which a substantially low maximum TON (591) has been recorded. Apart from this observation, on a general basis, the comparison of the light-driven $\mathrm{H}_{2}$ production performances suggests that the addition of substituents on the pyridine moiety (C2 and C4) is beneficial to enhance the photocatalytic ability of the threecomponent system. Conversely, the addition of substituents on the bipyridines ( $\mathbf{C} \mathbf{1}$ and $\mathbf{C} 3$ ) induces a substantial decrease of the photocatalytic efficiency with respect to the unsubstituted $\mathbf{C O}$ catalyst. Importantly, the electronic nature (i.e., EWG or EDG) of the substituents seems to play a minor role on the light driven $\mathrm{H}_{2}$ production performance than the substituent position. In this respect, the different overpotential for the hydrogen evolution reaction, associated to the electronic effect and position of the substituents (see above), do not provide a straightforward explanation of the photochemical hydrogen evolution performances. Therefore, we speculated that the difference in photosynthetic activity might reside in the rate of hydrogen formation associated to different mechanistic pathways which might occur using differently functionalized catalysts.

\section{Transient absorption spectroscopy}

Transient absorption spectroscopy measurements were performed in order to get a more detailed insight into the photocatalytic mechanism particularly as far as the catalyst activation (i.e., reduction) steps are concerned. As described for related photochemical systems, ${ }^{[7 b,}{ }^{11,}{ }^{23-24]}$ the first photoinduced events within the three-component system based on $\mathrm{Ru}(\mathrm{bpy})_{3}{ }^{2+}$, ascorbic acid, and the series of proposed cobalt catalysts involve bimolecular reductive quenching of the sensitizer by the ascorbate donor, followed by a bimolecular electron transfer from the reduced chromophore to the cobalt catalyst. ${ }^{[25]}$ This reaction sequence can be conveniently monitored by laser flash photolysis technique upon excitation of a solution containing $75 \mu \mathrm{M}$ $\mathrm{Ru}(\mathrm{bpy}) 3^{2+}, 0.1 \mathrm{M}$ ascorbic acid, and $0.2 \mathrm{mM}$ cobalt catalyst in 1.0 $\mathrm{M}$ acetate buffer at $\mathrm{pH} 4.0$ (see Section 6 of the SI). Transient absorption spectra were collected in the time range 2-100 $\mu$ s. The prompt transient spectrum, sampled at $2 \mu$ s time-delay (Figure $4 \mathrm{a}$, and Figure S6, S9, and S12), features a maximum at ca. $510 \mathrm{~nm}$, which can be assigned to the reduced $\mathrm{Ru}(\mathrm{bpy}){ }_{3}{ }^{+}$chromophore. ${ }^{[26]}$ This observation is indeed consistent with the expected reductive quenching of the triplet excited state of the $\mathrm{Ru}(\mathrm{bpy}) 3_{3}{ }^{2+}$ sensitizer by the ascorbate donor, occurring within the first $\mu \mathrm{s}$, as the first photochemical event. The following transient changes are biphasic in all cases. In particular, two main spectral changes take place within a $100 \mu \mathrm{s}$ timeframe. i) In the first $10 \mu \mathrm{s}$, the spectral 
evolution shows the decrease of the $510 \mathrm{~nm}$ absorption together with the growth of a new absorption in the red portion of the visible spectrum, leaving a transient signal with three relative maxima at ca. 500, 575, and $700 \mathrm{~nm}$ (Figure 4a for complex C1 and Figures S6a, S9a and S12a for C2, C3, and C4). ii) In the 10-100 $\mu$ s time scale the obtained transient spectrum decays to the baseline (Figure $4 \mathrm{~b}$ for complex C1 and Figures S6b, S9b and S12b for C2, C3, and C4). Process (i) can be ascribed to the occurrence of a bimolecular electron transfer from the reduced $\mathrm{Ru}(\mathrm{bpy})_{3}{ }^{+}$ chromophore to the cobalt catalyst. As a matter of fact, the kinetics are dependent on the catalyst concentration for all the tested complexes (Figure 5 for $\mathbf{C} 1$ and Figures S7, S10 and S13 for C2, C3, and C4). Under pseudo-first order kinetic conditions (i.e. $[\mathrm{Co}] \gg>\left[R u(b p y) 3_{3}{ }^{+}\right]$) the kinetic traces can be fitted using a single exponential. Subsequent plot of the observed rate $v s$ the catalyst concentration may allow for the estimation of the bimolecular rate constant for the electron transfer from the reduced chromophore to the catalyst. The values obtained are $k$ $=1.9( \pm 0.05) \times 10^{9} \mathrm{M}^{-1} \mathrm{~s}^{-1}$ for $\mathbf{C 1}, k=2.3( \pm 0.05) \times 10^{9} \mathrm{M}^{-1} \mathrm{~s}^{-1}$ for $\mathbf{C 2}$, $k=2.0( \pm 0.03) \times 10^{9} \mathrm{M}^{-1} \mathrm{~s}^{-1}$ for $\mathbf{C} 3$, and $k=2.2( \pm 0.05) \times 10^{9} \mathrm{M}^{-1} \mathrm{~s}^{-1}$ for C4, consistent with diffusion-limited bimolecular processes (i.e., those in which the diffusion of the reactants to form the encounter complex limits the overall electron transfer rate) ${ }^{[27]}$
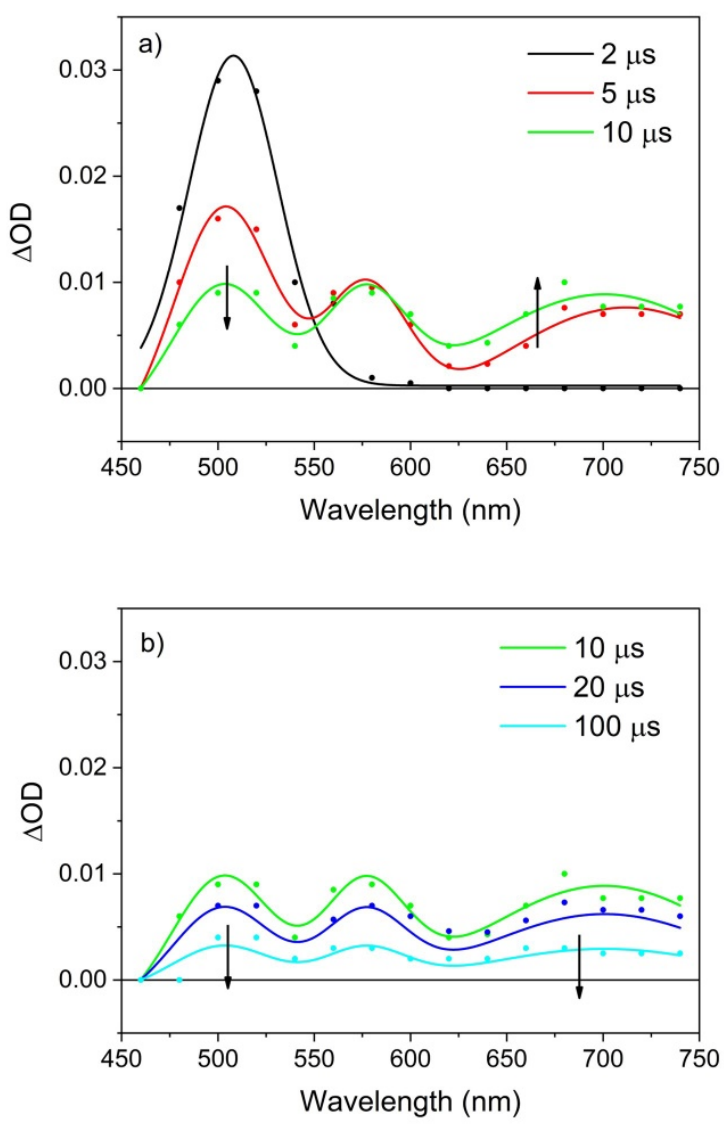

Figure 4. Spectral evolution of the transient absorption between (a) 2-10 $\mu$ s and (b) $10-100 \mu$ s obtained by laser flash photolysis (excitation at $532 \mathrm{~nm}$ ) of a 1.0 $\mathrm{M}$ acetate buffer solution at $\mathrm{pH} 4.0$ containing $0.1 \mathrm{M}$ ascorbic acid, $0.75 \mathrm{mM}$ of $\mathrm{Ru}(\mathrm{bpy}) 3^{2+}$ and $0.2 \mathrm{mMC}$.

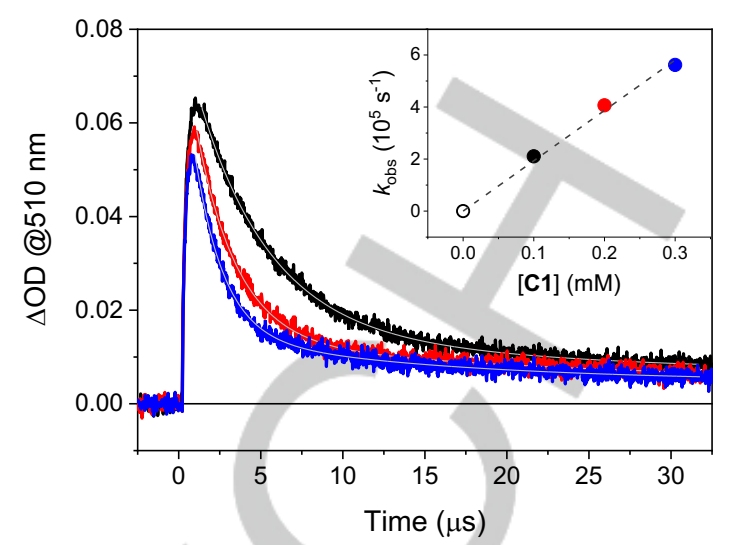

Figure 5. Kinetic traces of the decay at $510 \mathrm{~nm}$ obtained by laser flash photolysis (excitation at $532 \mathrm{~nm}$ ) of a $1.0 \mathrm{M}$ acetate buffer solution at $\mathrm{pH} 4.0$ containing $0.1 \mathrm{M}$ ascorbic acid, $0.75 \mathrm{mM}$ of $\mathrm{Ru}(\mathrm{bpy}) 3^{2+}$ and $0.1 \mathrm{mM}$ (black trace), $0.2 \mathrm{mM}$ (red trace) and $0.3 \mathrm{mM}$ (blue trace) $\mathbf{C} 1$; (inset) plot of the observed rate vs $\mathbf{C} 1$ concentration for the estimation of the bimolecular rate constant (from the slope, $\left.k=1.9( \pm 0.05) \times 10^{9} \mathrm{M}^{-1} \mathrm{~s}^{-1}\right)$.

Interestingly, these values are comparable within the series and also similar to those found for $\mathbf{C} \mathbf{0}$ and related cobalt polypyridine complexes. ${ }^{[11,23-24,28]}$ Concerning the nature of the species formed upon electron transfer from the photogenerated $\mathrm{Ru}(\mathrm{bpy}) 3^{+}$, the transient spectrum obtained is consistent with the formation of a low-valent $\mathrm{Co}(\mathrm{I})$ moiety, ${ }^{[11,24 \mathrm{~b}]}$ although the presence of structured bands probably suggests that the one-electron reduction of the cobalt complex might also involve some relevant electronic distribution over the chelating bipyridine ligands.

Process (ii), on the other hand, displays kinetics that are independent of the catalyst concentration and show a clear second-order decaying profile (Figure S5 for $\mathbf{C} 1$ and Figures S8, S11 and S14 for C2, C3, and C4). Similar to what has been observed in related systems, ${ }^{[24 b]}$ this process can be attributed to the re-oxidation of the cobalt complex by the photogenerated ascorbate radical. The rate constants obtained for this reaction are close to the diffusion-controlled kinetic regime for all complexes and thus comparable within the series. Taken together, the transient absorption studies point to the hypothesis that 1) for all studied catalysts $\mathbf{C 0 - 4}$ the first reduction step by photogenerated $\mathrm{Ru}(\mathrm{bpy}) 3+$ generates a similar $\mathrm{Co}(\mathrm{I})$ species, 2) the rate of such an electron transfer process is always close to the diffusion-limited kinetic regime and apparently unaffected by the presence of EWG/EDG substituents on either the bipyridine or pyridine moieties. Accordingly, from these data we can safely argue that the differences in light-driven hydrogen evolution activity observed using different catalysts cannot be attributed to the kinetics of the electron transfer processes from the photogenerated reducing agent (redox steps), but to the kinetics of the subsequent chemical steps (protonation).

\section{Computational analysis}

The electrochemical characterization of the cobalt complexes C0'-C4 in the presence of TFA as a proton source suggests that in light-driven hydrogen evolution experiments an ECEC process (Scheme 3a) is the dominating mechanism towards proton reduction. 


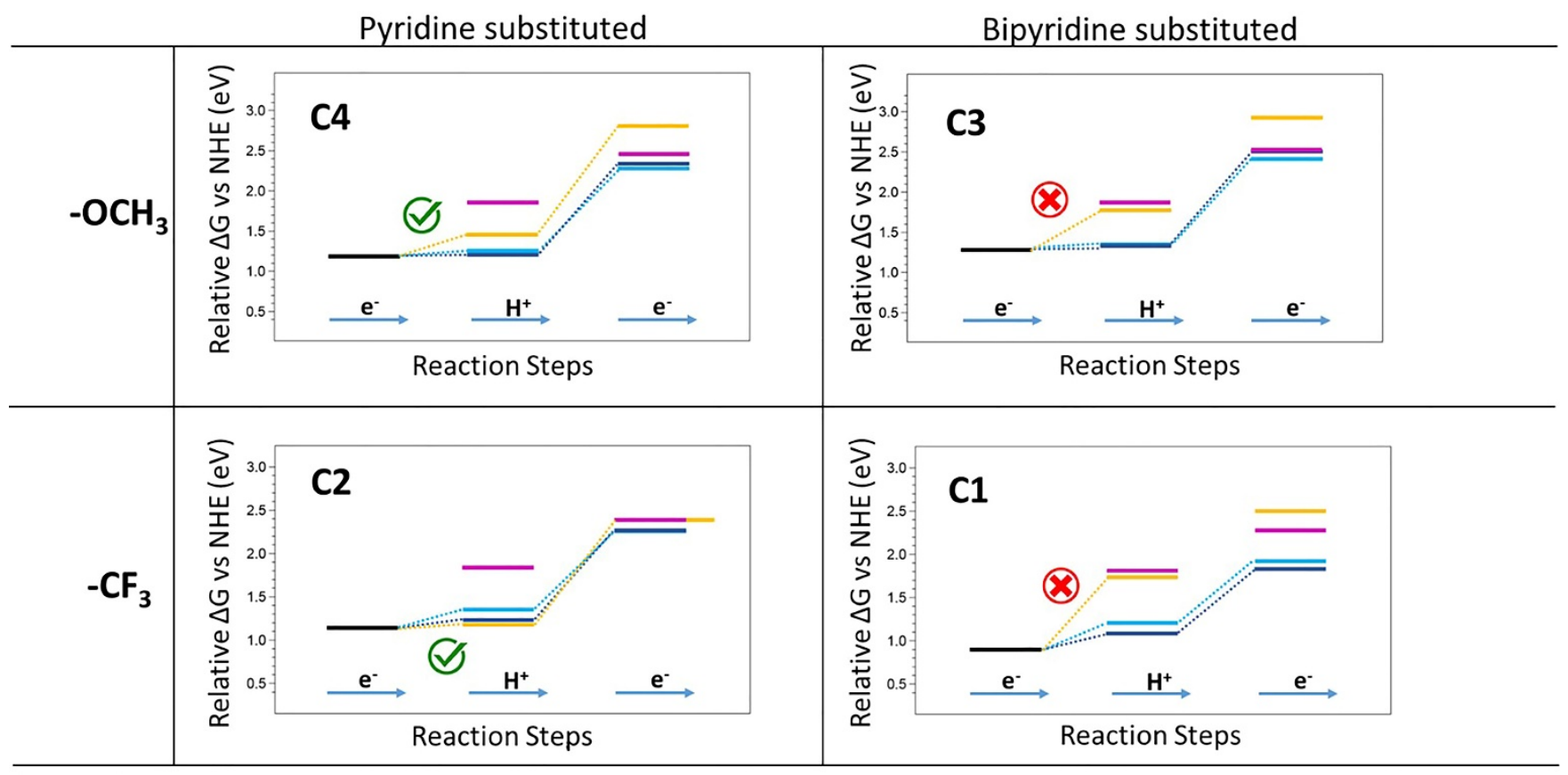

Legend:

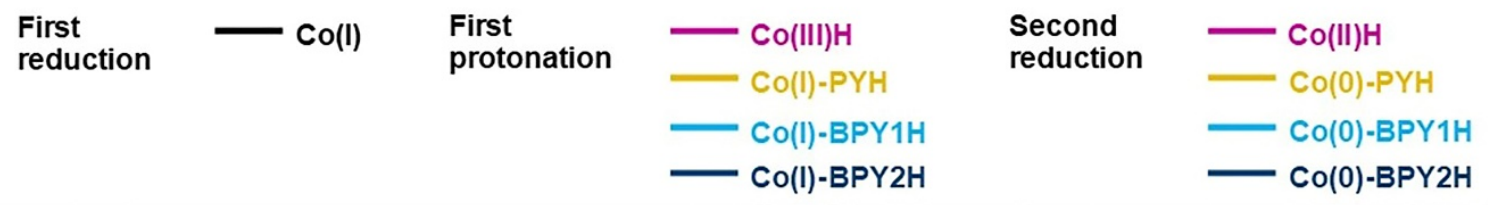

Figure 6. Calculated free energies profiles (in eV) for the possible reaction steps involved in the proposed mechanism (values for $\mathbf{C 0}$ in Figure. S17). The different reaction steps and paths, along with the relative free energy changes are given in Table S2 in SI.

Although an alternative mechanism is potentially available in the case of $\mathbf{C 1}((E) E C E C$, Scheme $3 b)$, its large energetic requirements (see above) make it extremely unlikely when driven by the photogenerated $\mathrm{Ru}(\mathrm{bpy}){ }_{3}{ }^{+}$reductant. ${ }^{[29]} \mathrm{A}$ computational analysis of the hydrogen evolution pathways of each cobalt complex has been thus performed in the framework of an ECEC mechanism (Scheme 3a) in order to shine light on the different reactivity towards proton reduction within the $\mathbf{C O}-\mathbf{C} 4$ series. Our previous mechanistic study on $\mathbf{C} 0,{ }^{[16]}$ indicates that, after the first EC step, the formation of ligand-protonated reduced Co(I) species is favored with respect to protonation of the metal center to give $\mathbf{C o}(\mathrm{III}) \mathrm{H}$. Therefore, besides $\mathbf{C o}(\mathrm{III}) \mathrm{H}$, we decided to model for all complexes all the possible intermediates, obtained upon protonation of one of the $\mathrm{N}$ atoms of the bipyridine ligands (BPY1H and BPY2H) or of the $\mathrm{N}$ atom of the pyridine ligand (PYH) (see Figure S15 in the SI for a further explanation of the nomenclature adopted). As we previously discussed, ${ }^{[16]}$ these are, in fact, the only sites leading to a de-coordination of the protonated $\mathrm{N}$ and to a stabilization of the intermediates. Indeed, the protonation of the other two $\mathrm{N}$ atoms of the bipyridine (BPY1' $H$ and BPY2'H) does not enable this de-coordination because of the geometrical constraints imposed by the methylamine and by the second coordinated pyridine. The relative free energy changes associated to the considered intermediates for each protonation and reduction step are plotted, against $\mathrm{NHE}$, in Figure 6 . In the case of complexes $\mathbf{C} 1$ and $\mathbf{C} 3$ (right panels in Figure 6), bearing substituents on the bipyridine, the energetical outline after the first reduction-protonation is similar to the one calculated for $\mathbf{C 0}$ (Figure S17), i.e., involving the formation of Co(I)-BPY1H/2H intermediates featuring a reduced metal center and a protonated bipyridine. For these two complexes formation of the Co(I)-PYH intermediate can be reasonably ruled out since it lies too high in energy with respect to $\mathbf{C o}(\mathbf{l})$ (0.84 and $0.49 \mathrm{eV}$ for $\mathbf{C} 1$ and $\mathbf{C} 3$, respectively, see Table S2), whereas protonation of the pyridine is slightly more feasible in CO, with Co(I)-PYH lying at $0.36 \mathrm{eV}$ with respect to $\mathrm{Co}(\mathrm{I})$. Interestingly, as shown in the left panels of Figure 6 , the introduction of substituents on the pyridine moiety (i.e., in complexes $\mathbf{C 2}$ and $\mathbf{C 4}$ ) results in a pronounced stabilization of the pyridine-protonated intermediate $\mathbf{C o}(\mathrm{I})-\mathbf{P Y H}$, regardless of the electronic nature of the substituent (i.e., EWG or EDG). Free energy differences of $0.07 \mathrm{eV}$ and $0.26 \mathrm{eV}$ with respect to $\mathbf{C o}(\mathrm{I})$, can be calculated for $\mathbf{C 2}$ and $\mathbf{C 4}$, respectively (Figure 6 and Table S2), indicating that the Co(I)-PYH intermediate is the most stable species for C2 after the first reduction-protonation sequence.

In the second reduction step (ECE), the formation of a $\mathrm{Co}(\mathrm{II}) \mathrm{H}$ intermediate, featuring a protonated metal center and a dangling pyridine moiety, ${ }^{[16]}$ is thought to be the key step before the second protonation and eventual $\mathrm{H}_{2}$ elimination. ${ }^{[30]}$ Since direct protonation of the metal center is unfeasible after the first reduction-protonation step $(0.6-0.9 \mathrm{eV}$ above $\mathrm{Co}(\mathrm{I})$, see data in Table S2), formation of $\mathbf{C o}($ II) $\mathbf{H}$ has to take place through an intramolecular proton transfer from the ligands to the metal taking place after the second reduction. ${ }^{[30-31]}$ Due to the relatively high 
energy of the Co(I)-PYH intermediate, in the case of complexes C1, and $\mathbf{C} 3$ the only available pathway is a Co(0)-BPY1H/2H $\rightarrow$ $\mathrm{Co}(\mathrm{II}) \mathrm{H}$ proton transfer. On the other hand, for the remaining complexes C2 and C4, a Co(0)-PYH $\rightarrow$ Co(II)H proton transfer represents an additional, favorable channel.

In this respect, while the Co(0)-BPY1H/2H $\rightarrow$ Co(II)H transformation (Figure 7) is slightly endergonic for $\mathbf{C O}(0.14 \mathrm{eV}$, $3.3 \mathrm{kcal} / \mathrm{mol}), \mathbf{C} 2(0.07 \mathrm{eV}, 1.7 \mathrm{kcal} / \mathrm{mol}), \mathbf{C} 3(0.02 \mathrm{eV}, 0.4$ $\mathrm{kcal} / \mathrm{mol})$, and $\mathbf{C} 4(0.19 \mathrm{eV}, 4.5 \mathrm{kcal} / \mathrm{mol})$, this process is largely

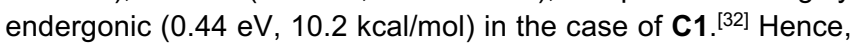
this unfavorable thermodynamics for the formation of the key Co(II)H intermediate possibly explains the lowest catalytic performance of $\mathbf{C} \mathbf{1}$ within the series of cobalt complexes. On the other hand, the $\mathbf{C o}(\mathbf{0})-\mathbf{P Y H} \rightarrow \mathbf{C o}(\mathrm{II}) \mathbf{H}$ reaction is always predicted to be a more favorable exergonic process (-2.3 to -9.5 $\mathrm{kcal} / \mathrm{mol}$, see Figure 8 , corresponding to -0.10 to $-0.41 \mathrm{eV}$ ). Considering this thermodynamic picture, and the possibility of achieving the $\mathbf{C o}$ (II)H intermediate by two channels (namely via proton transfer from both the bipyridine and pyridine protonated intermediates), we can already infer on the superior photochemical $\mathrm{H}_{2}$ evolution efficiencies of the pyridine-substituted catalysts C2 and C4 (Figure 3).

Although the energetic profiles discussed above provide a suitable framework to discuss the potential feasibility of the expected catalytic pathway, they do not provide information about the energy barriers for the intramolecular proton transfer reactions, which constitute a crucial parameter to establish the actual feasibility of the process. Estimation of energy barriers can be obtained by performing relaxed energy scans along the proton transfer "reaction coordinate" ( $\mathrm{N}_{\mathrm{BPY}}-\mathrm{H}-\mathrm{Co}$ distance), as reported in our previous work. ${ }^{[16]}$ By using this method, a barrier of $27-28 \mathrm{kcal} / \mathrm{mol}$ was estimated for the reaction $\mathrm{Co}(0)-\mathrm{BPY} 1 / 2 \mathrm{H}$ $\rightarrow \mathrm{Co}$ (II)H in the case of $\mathbf{C O}$. We have now calculated the transition states for the Co(0)-BPY1/2H $\rightarrow$ Co(II)H reactions for all C1-C4 catalysts. Such data are plotted in Figure 7, while the corresponding relaxed energy scans are reported in Figure S18 and S19. As is evident, the values obtained by the location of the transition states quantitatively agree with the results of the relaxed scans.
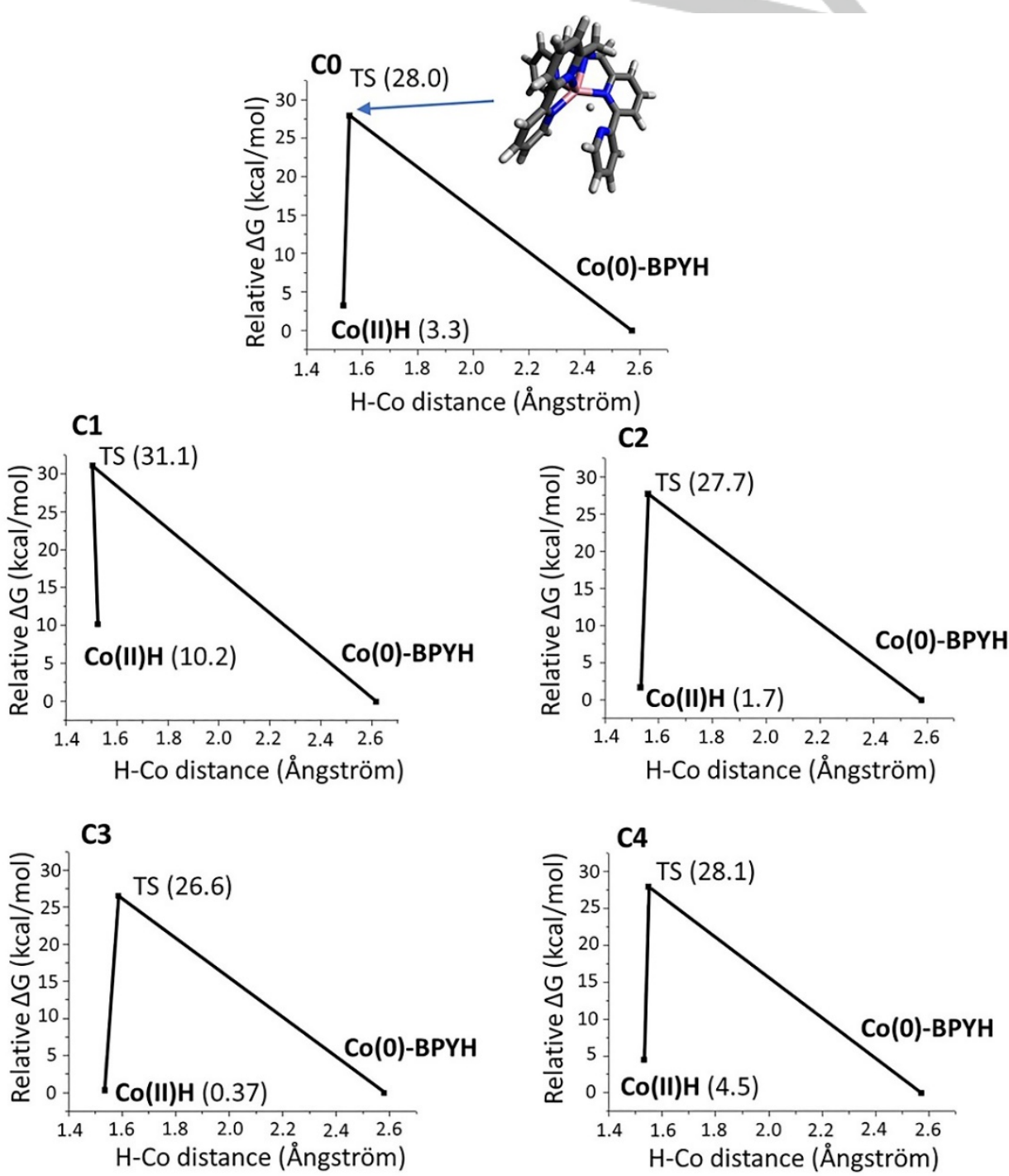

Figure 7. Calculated free energies barriers (in $\mathrm{kcal} / \mathrm{mol}$ ) in acetonitrile for the $\mathbf{C o}(\mathbf{0})$-BPY1H $\rightarrow$ Co(II)H proton transfer at the second reduction step, including the respective minima and the transition state (TS). ). For the latter, the energy value (in $\mathrm{kcal} / \mathrm{mol}$ ) with respect to the most stable minimum is given in brackets. For sake of comparison, the structure of TS for $\mathbf{C O}$ is also shown. 

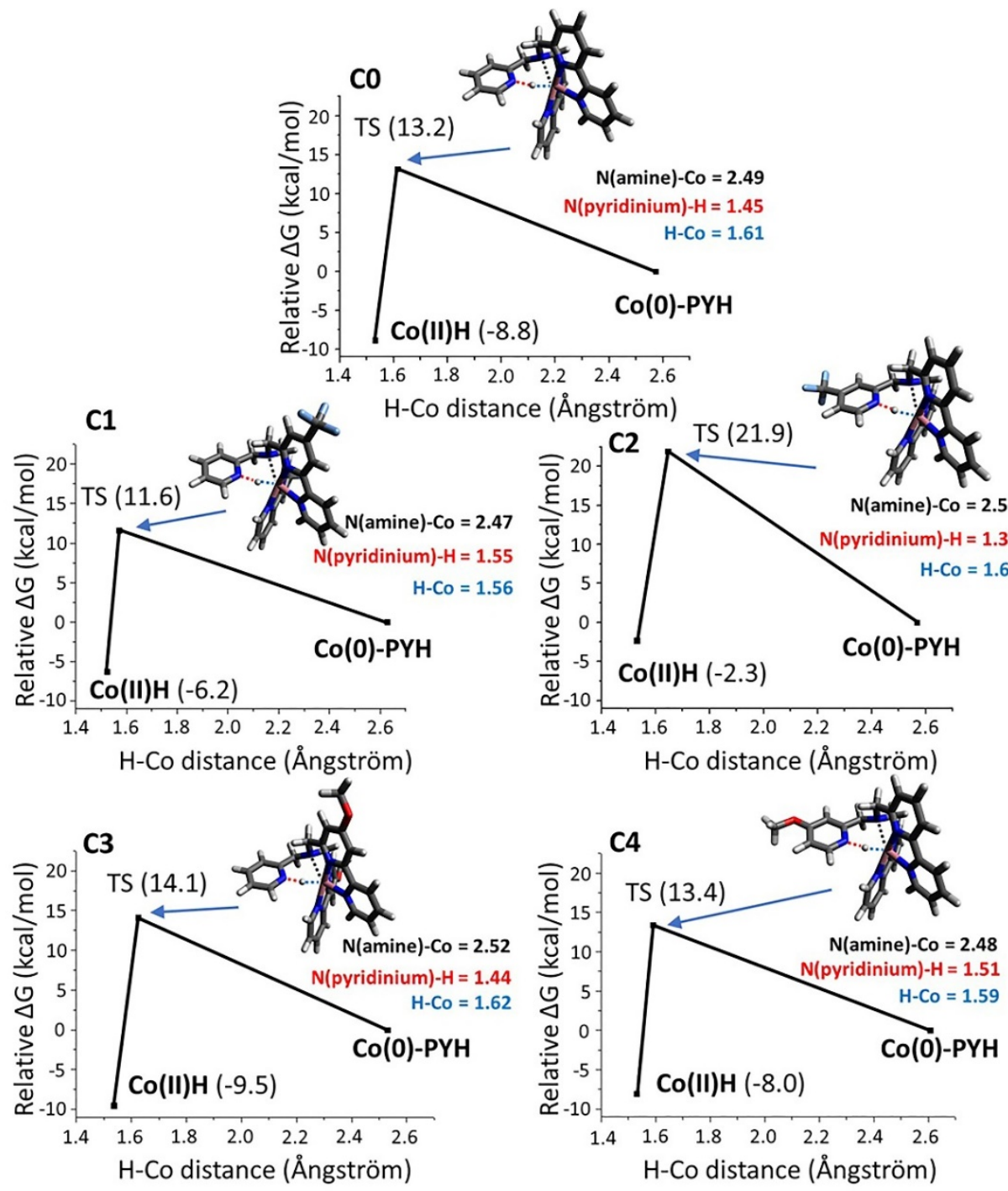

Figure 8. Calculated free energies barriers (in $\mathrm{kcal} / \mathrm{mol}$ ) in acetonitrile for the $\mathbf{C o}(\mathbf{0})-\mathbf{P Y H} \rightarrow \mathbf{C o}$ (II)H proton transfer at the second reduction step, including the respective minima and the transition state(TS). For the latter, the energy value (in $\mathrm{kcal} / \mathrm{mol}$ ) with respect to the most stable minimum is given in brackets. Moreover, each transition state structure is depicted, with the values in Ångström of the main distances involved.

In fact, the calculated barrier for the Co(0)-BPY1/2H $\rightarrow \mathrm{Co}(\mathrm{II}) \mathrm{H}$ process is about $27-28 \mathrm{kcal} / \mathrm{mol}$ for all the catalysts with the exception of $\mathbf{C} \mathbf{1}$, for which not only the process is notably endergonic (Figure 6) but an energy barrier exceeding $30 \mathrm{kcal} / \mathrm{mol}$ is calculated. Since this is the only possible pathway for the bipyridine-substituted complexes $\mathbf{C} 1$ and $\mathbf{C} 3$ (protonation of the pyridine is not energetically affordable), these data, along with the energetics in Figure 6, support the low catalytic activity of such complexes, as experimentally observed (Figure 3 ).

As shown in Figure 8 , on the other hand, significantly lower energy barriers (11-14 kcal $/ \mathrm{mol}$ ) are calculated for the Co(0)-PYH $\rightarrow \mathrm{Co}$ (II)H process, with the only exception of C2, for which we estimate about $22 \mathrm{kcal} / \mathrm{mol}$. This trend is confirmed also by the corresponding relaxed energy scans (Figure S19). ${ }^{[33]}$ Therefore, proton transfer from the pyridine to the metal center seems to be the energetically preferred channel to the formation of $\mathrm{Co}(\mathrm{II}) \mathrm{H}$ after the second reduction step considering both the $\Delta \mathrm{G}$ and the relative energy barrier. Since the Co(0)-PYH $\rightarrow$ Co(II)H pathway is available only for complexes C2 and C4, for which protonation of the pyridine (giving $\mathrm{Co}(\mathrm{I})-\mathrm{PYH}$ ), along with protonation of bipyridines, is accessible after the first reduction, these results well rationalize the superior catalytic performances of the pyridine-substituted complexes $\mathbf{C 2}$ and $\mathbf{C 4}$. In the case of the unsubstituted $\mathbf{C 0}$, the energy of the $\mathbf{C o}(\mathbf{I})-\mathbf{P Y H}$ intermediate obtained after the first EC sequence, in between the values observed for $\mathbf{C 1}, \mathbf{C} 3$ and $\mathbf{C 2}, \mathbf{C 4}$, cannot completely rule out the feasibility of a Co(0)-PYH $\rightarrow \mathbf{C o}($ II)H pathway. These results possibly explain the intermediate catalytic performance of the archetypical $\mathbf{C O}$ with respect to both the bipyridine-substituted and pyridine-substituted catalysts.

In summary, the computational analysis suggests that the different catalytic activity of the $\mathbf{C O}-\mathbf{C} \mathbf{4}$ complexes resides on the kinetics of hydrogen evolution which are determined by the formation of the key Co(II)H intermediate, occurring after an ECE process through an intramolecular proton transfer from a ligandprotonated species. ${ }^{[34]}$ In the case of the bipyridine-substituted 
catalysts, C1 and C3, formation of $\mathbf{C o}(\mathrm{II}) \mathrm{H}$, after reductionprotonation-reduction, takes place only through a $\mathrm{Co}(\mathrm{II}) \rightarrow \mathrm{Co}(\mathrm{I})$ BPY1/2H $\rightarrow$ Co(0)BPY1/2H $\rightarrow \mathrm{Co}(\mathrm{II}) \mathrm{H}$ sequence. The latter step is endergonic for both $\mathbf{C} 1$ and $\mathbf{C} 3$. The larger $\Delta \mathrm{G}$ in $\mathbf{C} 1$ than $\mathbf{C 3}$ (10.2 and $0.4 \mathrm{kcal} / \mathrm{mol}$, respectively) combined with the largest activation barrier in $\mathbf{C} 1(31 \mathrm{kcal} / \mathrm{mol})$ for this intramolecular proton transfer clearly establish the $\mathbf{C} \mathbf{1}<\mathbf{C} \mathbf{3}<\mathbf{C} \mathbf{0}$ trend in the light-driven catalytic activity, as experimentally observed. On the other hand, for the pyridine-substituted complexes $\mathbf{C 2}$ and C4, formation of $\mathrm{Co}$ (II)H after an ECE process is expected to occur mostly through a $\mathrm{Co}$ (II) $\rightarrow \mathrm{Co}(\mathrm{I})-\mathrm{PYH} \rightarrow \mathrm{Co}(0) \mathrm{PYH} \rightarrow \mathrm{Co}(\mathrm{II}) \mathrm{H}$ pathway involving pyridine-protonated intermediates. The exergonicity and small activation barriers for the intramolecular proton transfer to the metal centre unavoidably determine the superior catalytic performance of both $\mathbf{C 2}$ and $\mathbf{C} 4$ than the parent complex $\mathbf{C 0}$. The larger activation barrier in C2 than C4 $(22$ and $13 \mathrm{kcal} / \mathrm{mol}$, respectively) finally establishes the $\mathbf{C} 4>\mathbf{C 2}>\mathbf{C 0}$ trend in lightdriven hydrogen evolution activity, as experimentally followed. Overall, the striking observation from this investigation is that the substituent position rather than the type of group introduced is the dominating factor in enhancing the rate of hydrogen formation. Accordingly, it is not surprising that previous works trying to elucidate the role of the substituents on the light-driven hydrogen evolution activity by cobalt polypyridine complexes failed to find a general rule of thumb when considering the sole electronic effect imparted by EDGs or EWGs. In this respect, the exploitation of functional groups capable of facilitating the formation of the relevant $\mathbf{C o}(\mathrm{II}) \mathrm{H}$ via intramolecular proton transfer pathways at low activation energy appears as a general strategy to achieve improved catalytic performances.

\section{Conclusion}

A series of new cobalt polypyridyl complexes based on hexadentate ligands has been synthesized and characterized. EWG $\left(-\mathrm{CF}_{3}\right)$ and EDG $\left(-\mathrm{OCH}_{3}\right)$ groups were used to functionalize the archetypical $\mathbf{C O}$ complex ${ }^{[16]}$ by substitution at both bipyridine (C1 and $\mathbf{C} 3$, respectively) and pyridine (C2 and C4, respectively) moieties. The complexes were found to be able to catalyze proton reduction under light-driven conditions in the presence of $\mathrm{Ru}(\mathrm{bpy}){ }_{3}{ }^{2+}$ and ascorbic acid at $\mathrm{pH}=4$. TONs between $5520-591$ and maximum TOFs between 86.1 - $26.7 \mathrm{~min}^{-1}$ were reached according to the catalysts used. We found that the location of the substituents (i.e., on the pyridine or on the bipyridine moiety) has a more pronounced effect on the catalytic efficiency with respect to the electronic nature (i.e., EWG or EDG) of the substituent. Moreover, the introduction of these substituents on the pyridine, regardless of their donating or withdrawing nature, was able to improve the performance of the catalysts. Combined transient absorption measurements and DFT calculations indicate that the improved hydrogen evolution activity using the pyridinesubstituted complexes resides on the facile formation of the relevant $\mathbf{C o}($ II)H intermediate via intramolecular proton transfer pathways at low activation energy.

\section{Experimental Section}

\section{Synthesis and Characterization}

Details concerning the synthesis of the ligands and of complexes are given in the Section 2 of the Supporting Information (SI) file. Single crystals suitable for X-ray analysis were obtained by slow diffusion of diethyl ether in solutions of $\mathrm{CH}_{3} \mathrm{CN}$ containing the complexes. The compounds were fully characterized by HRESI-MS, elemental analysis, and X-ray diffractometry (details are given in SI, Section 2 and 10). Magnetic moments of the complexes were calculated with the Evans method (details are given in SI, Section 4). Deposition number CCDC-1050159 (C1), 1050160 (C2), 1050161 (C3) and 1050162 (C4) contain the supplementary crystallographic data for this paper. These data are provided free of charge by the joint Cambridge Crystallographic Data Centre and Fachinformationszentrum Karlsruhe Access Structures service www.ccdc.cam.ac.uk/structures."

\section{Electrochemical studies}

Cyclic voltammetry (CV) experiments were carried out at $0.1 \mathrm{Vs}^{-1}$ in $\mathrm{CH}_{3} \mathrm{CN}$ using $0.1 \mathrm{M} \mathrm{TBAPF}_{6}$ (tetrabutylammonium hexafluorophosphate) as the supporting electrolyte. A glassy carbon was used as working electrode, $\mathrm{Pt}$ as the counter electrode, and an $\mathrm{Ag}$ wire as the quasireference electrode. Ferrocene was employed as an internal standard to which the potential were referenced.

\section{$H_{2}$ production experiments}

Photochemical $\mathrm{H}_{2}$ production experiments were carried out in acetate buffer $(1.0 \mathrm{M})$ at $\mathrm{pH} 4.0$ in the presence of the catalyst $(1 \mu \mathrm{M}), \mathrm{Ru}(\mathrm{bpy}) 3^{2+}$ $(0.5 \mathrm{mM})$ and ascorbic acid $(0.1 \mathrm{M})$ at $20^{\circ} \mathrm{C}$. Led light at $475 \mathrm{~nm}$ with a power of $1.1 \mathrm{~W}$ was used as light source. In order to rule out the formation of nanoparticles due to decomposition of the catalysts, the experiments were replicated in the presence of $1 \mathrm{~mL} \mathrm{Hg}$ in reaction flasks. Figure S21 displays that the presence of mercury does not lead to any variation in the photocatalytic process, thus confirming the molecular nature of the catalysts for the time of the analysis. The parameters of the photochemical reactions, such as temperature and $\mathrm{pH}$, were chosen according to optimized conditions previously determined for $\mathbf{C} 0 .{ }^{[13]}$ For all systems, the hydrogen evolution reaches the plateau after 1-2 hours of irradiation, as shown by the obtained turnover numbers (TONs, expressed as $\left(\mathrm{mol} \mathrm{H}_{2}\right)$ (mol Cat. $\left.)^{-1}\right)$ and turnover frequencies (TOFs, expressed as $\left(\mathrm{mol} \mathrm{H}_{2}\right)(\mathrm{mol}$ Cat. $\left.)^{-1}(\mathrm{~min})^{-1}\right)$. Control experiments performed in the absence of catalyst, photosensitizer and light show no $\mathrm{H}_{2}$ evolution (Figure S22). Quantum yields were obtained according to the method described in the SI (Section 9).

\section{Transient absorption spectroscopy}

Nanosecond transient absorption measurements were performed with a custom laser spectrometer comprised of a Continuum Surelite II Nd:YAG laser (FWHM = $8 \mathrm{~ns}$ ) with frequency doubled $(532 \mathrm{~nm}, 330 \mathrm{~mJ})$ option, an Applied Photophysics Xe light source including a mod. $720150 \mathrm{~W}$ lamp housing, a mod. 620 power-controlled lamp supply and a mod. 03 - 102 arc lamp pulser. Laser excitation was provided at $90^{\circ}$ with respect to the white light probe beam. Light transmitted by the sample was focused onto the entrance slit of a $300 \mathrm{~mm}$ focal length Acton SpectraPro 2300i triple grating, flat field, double exit monochromator equipped with a photomultiplier detector (Hamamatsu R3896). Signals from the photomultiplier (kinetic traces) were processed by means of a TeledyneLeCroy 604Zi (400 MHz, $20 \mathrm{GS} / \mathrm{s}$ ) digital oscilloscope. Before all the measurements the solutions were purged with nitrogen for 10 minutes.

\section{Computational methods}

In order to have a quantitative comparison with our already published results we adopted the theoretical protocol and the global computational strategy employed in our previous works on heptacoordinate cobalt complexes. ${ }^{[13,16]}$ All the electronic structure calculations were carried out with the Gaussian09 package ${ }^{[35]}$ and density functional theory (DFT) was 
applied through the B3LYP functional[36] in combination with the $6-311 \mathrm{G}^{*}$ basis set. The solvent (acetonitrile) effects were taken into account by the integral equation formalism (IEF) variant of the polarizable continuum model $\left(\mathrm{PCM}^{[37]}\right)$, for comparison with the previously calculated values concerning $\mathbf{C O}_{0}{ }^{[16]}$ In agreement with the experimentally assessed and computationally confirmed ground state high spin configuration of the complex (charge +2 and spin multiplicity 4 ), all the reduced and protonated intermediates have been considered in their high-spin electronic configuration, that is $+1 / 0$ and spin multiplicity of $3 / 2$ for the singly/doubly reduced species, respectively. Redox potentials in acetonitrile for the complex, $\mathrm{Co}(\mathrm{II})$, and its reduced species, "formal $\mathrm{Co}(\mathrm{I})$ " and "formal $\mathrm{Co}(0)$ " were calculated as free energy differences in solution converted vs. $\mathrm{Fc} / \mathrm{Fc}^{+}$ by adding $-4.80 \mathrm{eV}$, according to ref. ${ }^{[18]}$. The Gibbs free energy in solution of a species $\mathrm{i}\left(\mathrm{G}^{\mathrm{i}}\right.$ solv $)$ is defined as $\mathrm{G}_{\text {solv }}=\mathrm{G}^{\mathrm{i}}$ vac $+\Delta \mathrm{G}^{\mathrm{i}}$ solv, where $\mathrm{G}^{\mathrm{i}}$ vac is the Gibbs free energy in gas phase (the gas phase energy with zero point energy and thermal corrections) and $\Delta G^{i}$ solv is the free energy of solvation. $\mathrm{G}^{\mathrm{i}} \mathrm{vac}$ is obtained by performing a single point calculation at the optimized geometry in vacuo, followed by frequency calculations in order to include the vibrational contribution to the total partition function. The solvation free

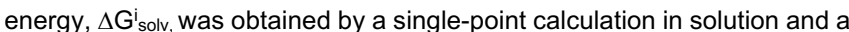
reference calculation in gas phase at the geometry optimized in solution, by using the IEFPCM approach and the gaussian03 default settings as implemented in Gaussian09. Similarly to the procedure reported in Ref. [38] to calculate the relative free energies for the considered reaction steps, we used values of $\mathrm{G}^{*}\left(\mathrm{H}^{+}(\mathrm{s})\right)=-266.5 \mathrm{Kcal} / \mathrm{mol}^{[39]}$ and $\mathrm{G}^{0}\left(\mathrm{e}^{-}(\mathrm{g})\right)=-0.868$ $\mathrm{Kcal} / \mathrm{mol}^{[40]}$ and a value of $-4.44 \mathrm{eV}$ for the vacuum level with respect to the Normal Hydrogen Electrode (NHE) in acetonitrile. In order to establish Gibbs free energy differences and energy barriers for proton transfer at the second reduction step (i.e. from pyridine and selected bipyridine moieties towards the metal center $\mathrm{Co}(\mathrm{II}) \mathrm{H})$, frequency calculations were computed for all stationary points (minima and transition states). For initial assessment and comparison purposes, relaxed scans were performed to evaluate the same proton transfer processes and, only in $\mathbf{C 4}$, when adding trifluoroacetic and acetic acids. Details on the calculation of the redox potentials, including the Gibbs free energy in solution, are given in $\mathrm{SI}$ (Section 1)

\section{Acknowledgements}

M. P. thanks the French National Research Agency within grant ANR JCJC HELIOSH2 (ANR-17-CE05-0007-01) and HPC resources from GENCI-CCRT/CINES (Grants 2018A0010810139) and from the LPCT local computing clusters. F. L. and A. R. thank the Swiss National Foundation (Grant 159716, FN 7359) for the financial support. M.N. acknowledges financial support from the University of Ferrara (FAR2019).

Keywords: cobalt $\cdot$ heptacoordinate complex $\cdot$ hydrogen $•$ photochemistry $\cdot$ structure-activity.

[1] a) Hydrogen and Fuel Cells: Fundamentals, Technologies and Applications, (Ed.: D. Stolten), Wiley-VCH, Weinheim, 2010; b) V. Balzani, A. Credi, M. Venturi, ChemSusChem 2008, 1, 26-58.

[2] Z. Han, R. Eisenberg, Acc. Chem. Res. 2014, 47, 25372544.

[3] a) S. Berardi, S. Drouet, L. Francàs, C. Gimbert-Suriñach, M. Guttentag, C. Richmond, T. Stoll, A. Llobet, Chem. Soc. Rev. 2014, 43, 7501-7519; b) P. Du, R. Eisenberg, Energy Environ. Sci. 2012, 5, 6012-6021.

[4] W. T. Eckenhoff, R. Eisenberg, Dalton Trans. 2012, 41, 13004-13021.

[5] a) M. L. Helm, M. P. Stewart, R. M. Bullock, M. R. DuBois, D. L. DuBois, Science 2011, 333, 863-866; b) T. Straistari, J. Fize, S. Shova, M. Réglier, V. Artero, M. Orio,
ChemCatChem 2017, 9, 2262-2268; c) A. Das, Z. Han, W. W. Brennessel, P. L. Holland, R. Eisenberg, ACS Catal. 2015, 5, 1397-1406; d) M. A. Gross, A. Reynal, J. R. Durrant, E. Reisner, J. Am.Chem. Soc. 2014, 136, 356-366.

[6] a) S. Kaur-Ghumaan, L. Schwartz, R. Lomoth, M. Stein, S. Ott, Angew. Chem. Int. Ed. 2010, 49, 8033-8036; b) C. Tard, C. J. Pickett, Chem. Rev. 2009, 109, 2245-2274; c) C. L. Hartley, R. J. DiRisio, M. E. Screen, K. J. Mayer, W. R. McNamara, Inorg. Chem. 2016, 55, 8865-8870.

[7] a) V. Artero, M. Chavarot-Kerlidou, M. Fontecave, Angew. Chem. Int. Ed. 2011, 50, 7238-7266; b) N. Queyriaux, R. T. Jane, J. Massin, V. Artero, M. Chavarot-Kerlidou, Coord. Chem. Rev. 2015, 304, 3-19; c) D. Z. Zee, T. Chantarojsiri, J. R. Long, C. J. Chang, Acc. Chem. Res. 2015, 48, 20272036; d) P. Zhang, M. Wang, X. Li, H. Cui, J. Dong, L. Sun, Sci. China Chem. 2012, 55, 1274-1282; e) T. M. McCormick, B. D. Calitree, A. Orchard, N. D. Kraut, F. V. Bright, M. R. Detty, R. Eisenberg, J.Am. Chem. Soc. 2010, 132, 1548015483; f) M. Natali, R. Argazzi, C. Chiorboli, E. lengo, F. Scandola, Chem. Eur. J. 2013, 19, 9261-9271; g) S. Varma, C. E. Castillo, T. Stoll, J. Fortage, A. G. Blackman, F. Molton, A. Deronzier, M.-N. Collomb, Phys. Chem. Chem. Phys. 2013, 15, 17544-17552; h) S. Grau, M. Schilling, D. Moonshiram, J. Benet-Buchholz, S. Luber, A. Llobet, C. Gimbert-Suriñach, ChemSusChem 2020, 13, 2745-2752; i) R. W. Hogue, O. Schott, G. S. Hanan, S. Brooker, Chem. Eur. J. 2018, 24, 9820-9832; j) S. Losse, J. G. Vos, S. Rau, Coord. Chem. Rev. 2010, 254, 2492-2504.

[8] a) L. Tong, L. Duan, A. Zhou, R. P. Thummel, Coord. Chem. Rev. 2020, 402, 213079; b) A. Mazzeo, S. Santalla, C. Gaviglio, F. Doctorovich, J. Pellegrino, Inorg. Chim. Acta 2021, 517, 119950.

[9] Y. Sun, J. Sun, J. R. Long, P. Yang, C. J. Chang, Chem. Sci. 2013, 4, 118-124.

[10] M. Nippe, R. S. Khnayzer, J. A. Panetier, D. Z. Zee, B. S. Olaiya, M. Head-Gordon, C. J. Chang, F. N. Castellano, J. R. Long, Chem. Sci. 2013, 4, 3934-3945.

[11] R. S. Khnayzer, V. S. Thoi, M. Nippe, A. E. King, J. W. Jurss, K. A. El Roz, J. R. Long, C. J. Chang, F. N. Castellano, Energy Environ. Sci. 2014, 7, 1477-1488.

[12] S. Schnidrig, C. Bachmann, P. Müller, N. Weder, B. Spingler, E. Joliat-Wick, M. Mosberger, J. Windisch, R. Alberto, B. Probst, ChemSusChem 2017, 10, 4570-4580.

[13] F. Lucarini, M. Pastore, S. Vasylevskyi, M. Varisco, E. Solari, A. Crochet, K. M. Fromm, F. Zobi, A. Ruggi, Chem. Eur. J. 2017, 23, 6768-6771.

[14] W. T. Eckenhoff, Coord. Chem. Rev. 2018, 373, 295-316.

[15] a) K. De Buysser, G. G. Herman, E. Bruneel, S. Hoste, I. Van Driessche, Chem. Phys. 2005, 315, 286-292; b) K. C. de Berg, K. J. Chapman, J. Chem. Educ. 2001, 78, 670-673.

[16] F. Lucarini, J. Fize, A. Morozan, M. Marazzi, M. Natali, M. Pastore, V. Artero, A. Ruggi, Sustainable Energy Fuels 2020, 4, 589-599.

[17] N. G. Connelly, W. E. Geiger, Chem. Rev. 1996, 96, 877910.

[18] a) J. Pommerehne, H. Vestweber, W. Guss, R. F. Mahrt, H. Bässler, M. Porsch, J. Daub, Adv. Mater. 1995, 7, 551-554; b) C. Fujisue, T. Kadoya, T. Higashino, R. Sato, T. Kawamoto, T. Mori, RSC Adv. 2016, 6, 53345-53350.

[19] V. Fourmond, P.-A. Jacques, M. Fontecave, V. Artero, Inorg. Chem. 2010, 49, 10338-10347.

[20] C. Costentin, J.-M. Savéant, ChemElectroChem 2014, 1, 1226-1236.

[21] S. P. Pitre, C. D. McTiernan, W. Vine, R. DiPucchio, M. Grenier, J. C. Scaiano, Sci. Rep. 2015, 5, 16397.

[22] A. Agosti, M. Natali, L. Amirav, G. Bergamini, ChemSusChem 2020, 13, 4894-4899.

[23] E. Deponti, M. Natali, Dalton Trans. 2016, 45, 9136-9147. 
[24] a) E. Deponti, A. Luisa, M. Natali, E. lengo, F. Scandola, Dalton Trans. 2014, 43, 16345-16353; b) W. M. Singh, M. Mirmohades, R. T. Jane, T. A. White, L. Hammarström, A. Thapper, R. Lomoth, S. Ott, Chem. Commun. 2013, 49 8638-8640.

[25] In principle a symmetric mechanism might be feasible involving oxidative quenching of the sensitizer by the catalyst, followed by recovery of the oxidized chromophore by the donor. However, in the photocatalytic experiments the concentration of the ascorbate donor is much larger than that of the cobalt catalyst which would make the oxidative quenching extremely inefficient even assuming a diffusion-controlled bimolecular rate.

[26] L. A. Kelly, M. A. J. Rodgers, J. Phys. Chem. 1994, 98, 6377-6385.

[27] R. A. Marcus, J. Chem. Phys. 1956, 24, 966-978.

[28] A. Lewandowska-Andralojc, T. Baine, X. Zhao, J. T. Muckerman, E. Fujita, D. E. Polyansky, Inorg. Chem. 2015, 54, 4310-4321.

[29] N. A. Carmo dos Santos, M. Natali, E. Badetti, K. Wurst, G. Licini, C. Zonta, Dalton Trans. 2017, 46, 16455-16464.

[30] A. Bhattacharjee, E. S. Andreiadis, M. Chavarot-Kerlidou, M. Fontecave, M. J. Field, V. Artero, Chem. Eur. J. 2013, 19, 15166-15174.

[31] E. J. Sundstrom, X. Yang, V. S. Thoi, H. I. Karunadasa, C. J. Chang, J. R. Long, M. Head-Gordon, J. Am. Chem. Soc. 2012, 134, 5233-5242.

[32] The large endergonicity observed in $\mathbf{C} 1$ possibly accounts for the low catalytic currents associated to the ECEC mechanism in the electrochemical assays with TFA (Figure 2a).

[33] The potential effect of an acid molecule (e.g., TFA or $\mathrm{CH}_{3} \mathrm{CO}_{2} \mathrm{H}$ ) hydrogen bonded to the pyridine- $\mathrm{N}$ atom was investigated for $\mathbf{C 4}$, finding out that it disfavors the process (Figure S20).
[34] Dihydrogen elimination, with an activation barrier in the range $7-10 \mathrm{kcal} / \mathrm{mol}$, is not expected to be kinetically relevant, see also ref. [16].

[35] M. J. T. Frisch, G. W.; Schlegel, H. B.; Scuseria, G. E.; Robb, M. A.; Cheeseman, J. R.; Scalmani, G.; Barone, V.; Mennucci, B.; Petersson, G. A.; Nakatsuji, H.; Caricato, M.; Li, X.; Hratchian, H. P.; Izmaylov, A. F.; Bloino, J.; Zheng, G.; Sonnenberg, J. L.; Hada, M.; Ehara, M.; Toyota, K.; Fukuda, R.; Hasegawa, J.; Ishida, M.; Nakajima, T.; Honda, Y.; Kitao, O.; Nakai, H.; Vreven, T.; Montgomery, J., J. A.; Peralta, J. E.; Ogliaro, F.; Bearpark, M.; Heyd, J. J.; Brothers, E.; Kudin, K. N.; Staroverov, V. N.; Kobayashi, R.; Normand, J.; Raghavachari, K.; Rendell, A.; Burant, J. C.; lyengar, S. S.; Tomasi, J.; Cossi, M.; Rega, N.; Millam, N. J.; Klene, M.; Knox, J. E.; Cross, J. B.; Bakken, V.; Adamo, C.; Jaramillo, J.; Gomperts, R.; Stratmann, R. E.; Yazyev, O.; Austin, A. J.; Cammi, R.; Pomelli, C.; Ochterski, J. W.; Martin, R. L.; Morokuma, K.; Zakrzewski, V. G.; Voth, G. A.; Salvador, P.; Dannenberg, J. J.; Dapprich, S.; Daniels, A. D.; Farkas, Ö.; Foresman, J. B.; Ortiz, J. V.; Cioslowski, J.; Fox, D. J., Gaussian 09, Revision A.1. Gaussian Inc.: Wallingford CT 2009.

[36] A. D. Becke, J. Chem. Phys. 1993, 98, 5648-5652.

[37] a) E. Cancès, B. Mennucci, J. Tomasi, J. Chem. Phys. 1997, 107, 3032-3041; b) B. Mennucci, E. Cancès, J. Tomasi, J. Chem. Phys. B 1997, 101, 10506-10517.

[38] J. T. Muckerman, E. Fujita, Chem. Commun. 2011, 47, 12456-12458.

[39] C. P. Kelly, C. J. Cramer, D. G. Truhlar, J. Phys. Chem. B 2007, 111, 408-422.

[40] J. E. Bartmess, J. Phys. Chem. 1994, 98, 6420-6424.

\section{Entry for the Table of Contents}

Insert graphic for Table of Contents here. ((Please ensure your graphic is in one of following formats))

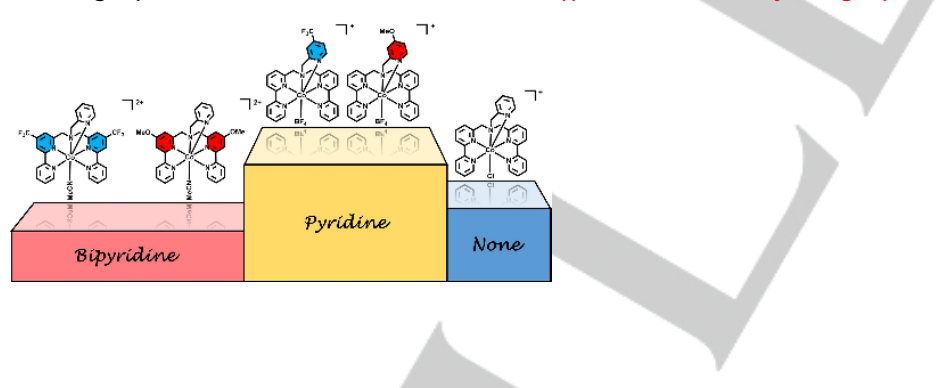

The structure-activity relationship of a family of heptacoordinate $\mathrm{Co}$ (II) complexes for light-triggered $\mathrm{H}_{2}$ evolution is reported. The complexes present a ligand scaffold including bipyridines and pyridines moieties functionalized with either electron donating or electron withdrawing groups. Results show that position plays a predominant role with respect to the electronic effect of the substituents.

Institute and/or researcher Twitter usernames: ((optional)) 